\title{
A EXPANSÃO DO CONTROLE POR MEIO DAS MEDIDAS CAUTELARES PESSOAIS DIVERSAS DA PRISÃO
}

\author{
THE EXPANSION OF CONTROL THROUGH THE ALTERNATIVE \\ PRECAUTIONARY PERSONAL MEASURES
}

\author{
Clara Maria Roman Borges* \\ João Rafael de Oliveira ${ }^{* *}$
}

\begin{abstract}
RESUMO: o presente artigo tem por objetivo analisar como as medidas cautelares pessoais alternativas à prisão, previstas na Lei $\mathrm{n}^{\circ} 12403 / 11$, foram responsáveis pela expansão do controle social realizado pelo sistema penal no Brasil. A partir da leitura das obras de Michel Foucault, atribui-se tal ampliação do controle punitivo à experiência contemporânea de uma sociedade de controle nos países ocidentais, que assegura sua manutenção com o estabelecimento de uma biopolítica e do neoliberalismo. Verifica-se como as novas medidas cautelares vêm ao encontro desta nova ordem social, que estabelece a vigilância permanente sobre os indivíduos.
\end{abstract}

PALAVRAS-CHAVE: Biopolítica. Medidas Cautelares Pessoais Alternativas. Neoliberalismo. Sociedade de Controle.

ABSTRACT: This article aims to analyze how the personal precautionary measures, alternative to imprisonment under Law $\mathrm{n}^{\circ} 12403 / 11$, were responsible for the expansion of social control exercised by the criminal justice system in Brazil. From reading the works of Michel Foucault, this expansion of punitive control is assigned to the contemporary experience of control society in Western countries, which ensures its maintenance with the establishment of a biopolitics and the neoliberalism. This denotes how the new precautionary measures match with this new social order, which establishes a permanent surveillance over individuals.

KEYWORDS: Alternative personal precautionary measures. Biopolitics. Control Society. Neoliberalism.

\section{INTRODUÇÃO}

Sabe-se que a Lei $n^{0}$ 12403/11 (BRASIL, 2011) ampliou o rol de medidas cautelares pessoais diversas da prisão previstas na legislação processual penal brasileira desde 1941, com o objetivo de tornar o encarceramento medida excepcional a ser decretada pelo juiz na

\footnotetext{
* Mestre e Doutora em Direito pela Universidade Federal do Paraná. Professora Adjunta de Direito Processual Penal no Curso de Graduação e no Programa de Pós-Graduação em Direito da UFPR. Professora Titular do Curso de Direito da Universidade Positivo.

** Mestrando em Direito do Estado no Programa de Pós-Graduação em Direito da UFPR. Professor de Direito Processual Penal nas Faculdades Integradas do Brasil - UniBrasil. Advogado Criminal.
} 
fase de investigação preliminar ou processual, apenas para garantir a conveniência da instrução processual, assegurar a aplicação da lei penal ao final da persecução do crime e, ainda, garantir a ordem pública ou econômica.

Então, com o propósito nobre de desafogar os cárceres brasileiros, que se encontram há muito precarizados em suas estruturas e incapazes de assegurar condições mínimas de sobrevivência aos condenados, bem como de tornar a prisão um lugar apenas para aqueles que praticaram crimes graves e de reconhecida relevância social, a nova lei estabeleceu uma série de restrições, que vão desde a proibição de frequentar determinados lugares, passando pelo monitoramento eletrônico do investigado ou acusado, até a entrega compulsória de passaportes para evitar a privação completa da liberdade.

Assim, para muitos estudiosos do direito, esta alteração legislativa significou um grande avanço, no sentido de estabelecer mecanismos aptos a conter o poder punitivo estatal, que nos últimos anos demonstrou vertiginoso crescimento, com as novas leis que aumentaram o número de crimes, as penas e cassaram garantias processuais.

Contudo, não se pode ser ingênuo a ponto de pensar que para manter estável uma coletividade marcada pelas desigualdades e pela violência delas decorrente, numa sociedade como a brasileira, em que o controle social é intenso, o legislador estabeleceria medidas aparentemente liberatórias sem qualquer objetivo de manter o arranjo dos jogos de poder ou de continuar expandindo a atuação do sistema penal.

Neste sentido, o presente texto pretende analisar como as medidas cautelares diversas da prisão, concebidas recentemente no ordenamento jurídico brasileiro, vão ao encontro desta expansão do controle social penal, própria de uma sociedade de controle como a brasileira.

Para cumprir tal intento, optou-se por compreender o surgimento da sociedade de controle a partir da obra de Michel Foucault, um dos autores a perceber suas nuanças, para além da ficção, ainda na década de 70 do século passado, em que pese tantos outros ${ }^{1}$ tenham tratado de maneira original desta temática. Portanto, entende-se que é imprescindível passar pelo estudo da biopolítica e do neoliberalismo, considerados elementos necessários para o desenvolvimento da sociedade de controle, para ao final verificar como e por que as medidas cautelares pessoais diversas da prisão têm se prestado ao controle das populações.

\footnotetext{
${ }^{1}$ São exemplos: Gilles Deleuze (1996), Zygmunt Bauman (2003), Giles Lipovetski (2004), Ulrich Beck (2010) e Manuel Castells (2005).
} 


\section{A BIOPOLÍTICA E O CONTROLE DAS POPULAÇÕES}

Segundo Michel Foucault (1999), nos séculos XVI e XVII o capitalismo industrial exigiu a constituição de um poder que investisse sobre os corpos de modo a adestrá-los, vigiálos, controlá-los, assujeitá-los e, consequentemente, torná-los mais producentes, numa relação de docilidade-utilidade ou docilidade-produção. Neste momento, uma nova mecânica disciplinar de poder se difundiu e passou a permear todas as relações sociais.

Assim, ao se generalizarem por toda a sociedade para possibilitar o funcionamento do capitalismo, as disciplinas utilizaram técnicas de distribuição, controle e organização dos corpos com intuito de aumentar suas forças para torná-los mais úteis e eficazes, e ao mesmo tempo de diminuí-las, para torná-los dóceis e obedientes.

Em suma, as práticas disciplinares de poder investiram sobre a coletividade para corrigir os indivíduos a partir de uma série de técnicas de organização dos espaços, de controle do tempo, de vigilância e registro do comportamento dos indivíduos, que deram lugar ao nascimento de determinados saberes, nos quais o modelo prioritário de estabelecimento da verdade era o exame. Assistiu-se à formação do que Michel Foucault (1994b, p. 173-204) chamou de sociedade panóptica, que assegurou inicialmente a formação de mão de obra para as fábricas e mais tarde a docilização do exército de trabalhadores excedentes.

De acordo com Salma Muchail (1986, p. 199), nessas sociedades invadidas pelas disciplinas se instaurou "um modo de poder onde a sujeição não se faz apenas na forma negativa de repressão, mas, sobretudo, ao modo mais sutil do adestramento, da produção positiva de comportamentos que definem o indivíduo ou o que ele deve ser segundo o padrão de normalidade."

Contudo, nos séculos XVIII e XIX, por força dos movimentos migratórios decorrentes da expansão dos mercados, que incrementaram multiplicidades e pluralidades nas populações, as sociedades ocidentais viram surgir os biopoderes, que implicaram a sofisticação das técnicas disciplinares para governar as populações a partir do processo de assunção da vida pelo poder ou a tomada de poder sobre o homem enquanto ser vivo.

Este processo, que segundo a tese foucaultiana tende à estatização do biológico, perverte por completo a ideia do poder fundado na teoria clássica da soberania, segundo a qual o Estado, na figura do soberano, exerce sobre os indivíduos o poder de vida e morte.

Sabe-se que para esta teoria o exercício do direito de vida e de morte pelos súditos depende da vontade do soberano; isto é, cabe ao soberano exercer seu poder de dizer quem 
tem direito de estar vivo ou, eventualmente, morto.

Contudo, é preciso admitir que a concretização deste poder soberano de vida e morte ocorre de maneira assaz paradoxal, já que o poder do soberano sobre a vida só se exerce a partir do momento em que o soberano pode matar.

Note-se por este viés que o poder de matar do soberano é que detém efetivamente em si a essência do próprio poder de vida e de morte dos súditos, ou seja, "é porque o soberano pode matar que ele exerce seu direito sobre a vida" (FOUCAULT, 1999, p. 287). Isto significa que há uma verdadeira dissimetria no exercício do poder soberano de vida e morte, pois da forma como funciona não faz viver ou morrer, nem deixa viver ou morrer, mas faz morrer e deixa viver.

Deste modo, quando na segunda metade do século XVIII surge uma nova forma do poder de investir sobre a vida, o poder soberano de fazer morrer ou deixar viver não vai ser apagado, mas perpassado, penetrado de maneira a se transformar num poder de viver e de deixar morrer.

Obviamente, esta transformação não ocorreu de repente; ao contrário, é produto de um processo lento de apropriação e modificação das práticas disciplinares de modo que pudessem ser utilizadas a serviço do Estado.

Munida de novos instrumentos, esta nova tecnologia de poder não age mais sobre o corpo individual de maneira a distribuí-lo, organizá-lo, controlá-lo e torná-lo mais útil; o seu alvo é a multiplicidade dos homens, a massa global, que deve ser governada por meio da regulamentação de seus processos de vida, como o nascimento, a morte, a produção, as doenças (FOUCAULT, 1994a, p. 605, v. III).

No dizer de Michel Foucault (1999, p. 289), “depois da anátomo-política do corpo humano, instaurada no decorrer do século XVIII, vemos aparecer, no fim do mesmo século, algo que já não é uma anátomo-política do corpo humano, mas que eu chamaria de uma 'biopolítica' da espécie humana."

Portanto, entende-se que essa biopolítica tem por finalidade controlar os processos de natalidade, mortalidade, longevidade e o modo de vida do homem, para que a partir de sua regulamentação possa alcançar a normalização das grandes populações.

Para atingir seu objetivo, primeiramente ela parte da medição estatística, do mapeamento, do exame desses fenômenos; isto é, preocupa-se com sua forma, natureza, extensão, duração, intensidade, para, num segundo momento, constituir saberes capazes de intervir diretamente sobre eles.

Como exemplo, o filósofo francês cita as observações feitas, a partir do século 
XVIII, sobre a natalidade e as endemias e o consequente surgimento de uma medicina dirigida à higiene pública, que coordena tratamentos médicos, centraliza informações, adquire aspecto de campanha de aprendizado e promove a medicalização da população (FOUCAULT, 1999, p. 291).

Outro âmbito de intervenção da biopolítica é aquele dos fenômenos que, por acidente ou natureza, relegam os indivíduos para fora dos campos de atividade e de capacidade, tais como as anomalias, a velhice, as mutilações. Neste caso, a regulamentação é realizada por meio de mecanismos racionais de assistência, como os seguros, a poupança, a previdência etc.

Esta nova tecnologia política não deixa, ainda, de se preocupar com os efeitos que as relações humanas provocam nos meios geográfico, climático, hidrográfico; mais especificamente, com os problemas ambientais, seus efeitos nocivos à saúde do homem etc. Neste momento, surge o problema da cidade e, para saná-lo, constitui-se um saber destinado à sua urbanização e ao seu planejamento (ORDOVAS, 2000).

Em suma, a biopolítica extrai, desta medição dos fenômenos que envolvem o homem ser vivo, o seu saber, e define o campo de intervenção de seu poder sobre a multiplicidade deles.

Noutros termos, essa intervenção ocorre sempre em nível global ou populacional, de modo a estabelecer mecanismos reguladores de fenômenos como natalidade, morbidade e longevidade, e assim exercer o poder de fazer viver (FOUCAULT, 1999, p. 294).

Veja-se que a manifestação concreta desta nova tecnologia de poder é percebida justamente na desqualificação progressiva que realiza da morte por força deste cuidado com a vida.

Sabe-se que desde o século XVIII o mundo ocidental assiste à progressiva desritualização da morte, que deixou de ser objeto de cerimônias brilhantes e frequentadas por toda a sociedade e passou a ser ocultada e celebrada por rituais privados, simplórios e breves. Assiste-se, então, a um paulatino desinteresse pelo poder sobre a morte e pelo deixar morrer, bem como a uma preocupação exacerbada com a vida ou com o fazer viver ${ }^{2}$.

Ainda em relação à biopolítica, é preciso salientar que sua tecnologia regulamentadora não eclipsou a tecnologia disciplinar; ao revés, ambas convivem e se sobrepõem de modo a diagramarem todo o corpo social com suas práticas.

Isto acontece desde o período de transição da soberania para a nova mecânica de

\footnotetext{
${ }^{2}$ Essa preocupação do biopoder com o fazer viver não o impede de causar a morte, caso esta seja necessária para garantir a vida da população; assim se justificam as guerras, o racismo etc. (cf. FOUCAULT, 1999, p. $49-73$ e p. 285-315).
} 
poder normalizador, como se pode observar no funcionamento das lettres de cachets.

As lettres de cachets, surgidas na França do século XVIII, eram cartas escritas por ordem real, referendadas por um secretário de Estado e lacradas com o selo do rei. Determinavam o confinamento administrativo e, consequentemente, a intervenção do poder do Estado, ainda que monárquico, na vida íntima das famílias.

Este mecanismo não era uma lei ou decreto, mas uma ordem real que recaía sobre um indivíduo para obrigá-lo a alguma coisa, que poderia ser desde o casamento até o confinamento.

Segundo Michel Foucault, os pedidos das lettres de cachet eram direcionados "tanto ao comissário de polícia quanto ao palácio do rei, para obter do soberano uma ordem de restrição de liberdade do indivíduo (que pode ser uma residência forçada, um exílio, mas, o mais comum, um confinamento).” (FOUCAULT; FARGE, 1982, p. 9)

Deste modo, as lettres de cachet eram emitidas pelo rei para vigiar, controlar as famílias e também, em última instância, para intervir diretamente na organização da sociedade, o que denota tanto a sua atuação em nível disciplinar, ao determinar o confinamento, quanto em nível bipolítico, ao transformar os problemas do âmbito privado em problemas públicos ou atinentes a toda sociedade (FOUCAULT, 1996).

Resta demonstrado, portanto, que as disciplinas e os biopoderes atuam articulados; mais especificamente, num determinado nível atua a tecnologia centrada no corpo, que manipula suas forças de modo a torná-las úteis e dóceis; noutro, funciona a tecnologia centrada na vida, que controla a série de eventos fortuitos que podem ocorrer numa massa viva, para normalizar e governar.

Nas palavras de Michel Foucault (1999, p. 294), “temos, pois, duas séries: a série corpo-organismo-disciplina e instituições; e a série população-processos biológicosmecanismos regulamentadores.",3

Aliás, a articulação entre esses níveis tecnológicos só é possível porque existe um elemento capaz de circular entre as disciplinas e os biopoderes, de se aplicar tanto ao corpo quanto à população, de controlar a ordem disciplinar do corpo e ao mesmo tempo os acontecimentos aleatórios de uma multiplicidade biológica - esse elemento é a norma.

A norma é vista pelo filósofo francês como "uma maneira de o grupo se dotar de uma medida comum segundo um rigoroso princípio de auto-referência, sem recurso a

\footnotetext{
${ }^{3}$ Note-se que neste esquema o filósofo francês frisa que o lugar da biopolítica é o do Estado, já o da disciplina é por excelência o da instituição, mas não quer dizer que as disciplinas fiquem restritas à instituição, pois seus exemplos várias vezes ressaltam que elas também perpassam os aparelhos estatais, tal como a polícia.
} 
nenhuma exterioridade, quer seja a de uma idéia, quer a de um objeto." (EWALD, 1993, p. 108)

Em outras palavras, trata-se de um critério que fixa uma medida comum a todos os integrantes de um grupo, de modo a torná-los visíveis e particularizados como grupo e sem excluir ninguém, mesmo aqueles que deixam de observá-la.

Esse critério pode ser disciplinar ou uma

(...) medida que permite que se separe no interior de um grupo determinado duas categorias (talvez fosse mais apropriado dizer dois estados) de indivíduos normais: os indivíduos "normais", que são aqueles que coincidem com o perfil estabelecido por essa medida, e os indivíduos "anormais", que são aqueles que, de algum modo, se afastam desse perfil. (FONSECA, 2002, p. 180)

Ressalte-se que esta separação entre normais e anormais não situa estes fora do critério de sua separação; ao contrário, o anormal tem a mesma natureza do normal e a única diferença diz respeito à posição que ocupa em relação à norma.

Marcio Alves da Fonseca exemplifica que no domínio das formas de punição a prisão serve de instituição disciplinar ou de lugar de efetivação da norma como medida de produção de uma individualidade normalizada; mais especificamente, ela separa os delinquentes dos não delinquentes:

\begin{abstract}
Afirmar que a prisão produz a delinqüência significa reconhecer sua função disciplinar de produtora de individualidade, uma individualidade especificada na forma de um sujeito patologizado. Pela disciplina, a prisão determina que certas condutas, que determinadas histórias pessoais, que certas índoles identifiquem "algo", identifiquem um "modo de ser" a que se pode chamar de "delinqüência". Esta seria uma forma de existência definida e descrita como "anormal" quando comparada com outras formas de existência definidas e descritas como "normais". (FONSECA, 2002, p. 1810)
\end{abstract}

Por outro lado, o critério estabelecido pela norma pode ser regulamentar - mais especificamente, uma medida deduzida da curva de normalidades de certo corpo social a partir de estatísticas de medições da população; ou seja, um critério que parte do que se entende por normal numa dada sociedade para estabelecer medidas de gestão e governo da população, dirigidas tanto para fazê-la viver quanto deixá-la morrer.

O mais importante a ser observado nesses critérios ou normas é que de um modo ou de outro eles classificam, valoram todos os indivíduos de uma sociedade como normais ou anormais, isto é, constituem aquilo que Michel Foucault chamou de sociedade normalizadora. Aliás, em nome da verdade estabelecida pela norma se conduzem as populações, a partir das conhecidas técnicas de pastoreio que vicejaram na Idade Média, no seio da Igreja, para guiar os rebanhos de fiéis (FOUCAULT, 1998). 
Sentenciava o filósofo francês que desta sociedade ninguém escapa, pois todos os indivíduos se encontram de alguma forma embaraçados na rede de poder que a perpassa; noutros termos, não há lado de fora nestes jogos de poder e de dominação.

Além disso, é preciso ressaltar que o incremento da vida da população não se separa da produção contínua de morte, que ocorre no interior e no exterior da comunidade para afastar aquele que é perigoso para a segurança da comunidade (FOUCAULT, 2008b). Neste momento, explica-se o racismo, que deixa de ser simplificadamente a expressão do ódio entre raças ou religiões, e passa a servir como justificativa legítima para a implementação da ação mortífera dos Estados (DUARTE, 2009, p. 42).

Ora, a partir desta análise é possível explicar o nazismo, que tratava de exterminar raças supostamente inferiores por meio do aniquilamento, sob o argumento de que colocavam em perigo a raça ariana; ou ainda, os motivos que levam a sociedade brasileira a relegar a ralé à morte nos precários hospitais públicos ou nos cárceres desumanos de nosso país.

Note-se que esta sociedade normalizadora, marcada pela biopolítica, é o campo fértil para o desenvolvimento da sociedade de controle, pois a gestão das populações exige a observação minuciosa dos fenômenos da vida da comunidade, o que demanda o exame e o cadastramento dos indivíduos; noutras palavras, para que se possa fazer viver essas populações é preciso controlar os fenômenos da vida dos indivíduos e vigiá-los permanentemente. Deste modo, pode-se concluir que a apropriação da vida pelo Estado é um passo importante para o estabelecimento da sociedade de controle, que ganha seu devido espaço na contemporaneidade com o desenvolvimento do neoliberalismo.

\section{O NEOLIBERALISMO E A SOCIEDADE DE CONTROLE}

É preciso reconhecer que Michel Foucault tem uma visão peculiar a respeito do neoliberalismo, talvez menos trágica do que aquelas que circulam no universo da literatura jurídica, nas quais o mercado se expande a níveis inimagináveis, sem qualquer intervenção estatal, promovendo uma exclusão próxima da insuportabilidade, amenizada pelo aparato penal estatal que neutraliza aqueles que não consomem e buscam violentamente sua inserção social.

Aliás, o filósofo francês alertava que, ao se falar de neoliberalismo, surgem frequentemente três espécies de explicação para definir este fenômeno. Do ponto de vista

\footnotetext{
${ }^{4}$ Termo utilizado por Jessé Souza (2011) para designar o grupo de brasileiros economicamente desfavorecidos, despossuídos de capital cultural para buscar a ascensão social.
} 
econômico, é possível dizer que consiste na reativação de velhas teorias econômicas liberais; do ponto de vista sociológico, é responsável por instaurar na sociedade relações estritamente mercantis, e do ponto de vista político, apresenta-se como máscara para uma insidiosa intervenção generalizada e administrativa do Estado (FOUCAULT, 2008a, p. 179).

Contudo, ele acreditava que o neoliberalismo se tratava de outra coisa, na medida em que tem como desafio não mais o estabelecimento de um espaço livre na sociedade política para o desenvolvimento e autorregulação do mercado, como queria o liberalismo clássico, mas a projeção dos princípios formais de uma economia de mercado numa arte geral de governar. Por este motivo, o neoliberalismo não mais se situará sob o signo do laissez-faire, e sim, sob o signo da vigilância e intervenção permanente do Estado, que passa a funcionar de acordo com os princípios formais da economia de mercado (FOUCAULT, 2008a, p. 201).

Isso influencia diretamente nas relações sociais, que passam a não serem lidas estritamente como mercantis, isto é, marcadas pela troca de mercadorias, nos termos aventados pelo liberalismo clássico, mas empresariais e pautadas pela concorrência. Trata-se da tentativa neoliberal de decifração em termos econômicos de comportamentos sociais tradicionalmente não econômicos (FOUCAULT, 2008a, p. 337).

Para exemplificar, cita-se a transformação da família numa empresa. Isso significa que a entidade familiar não é mais exclusivamente um espaço para trocas mercantis ou de reunião de patrimônio - trata-se de uma área na qual se produz capital humano, pois a mãe investe seu tempo, seus cuidados e seu afeto para que o filho se torne adulto e produza renda, isto é, um salário para ele e uma renda psíquica para ela, por conta do seu esforço bem sucedido.

Nesse sentido, é possível inclusive entender por que as famílias de maior renda passam a ter menos filhos do que as famílias de baixa renda. Note-se que uma família que possui um capital humano elevado, uma renda elevada, tem como projeto econômico a transmissão aos filhos de um capital humano tão elevado quanto o deles, e para tanto precisam investir pesadamente na sua educação, na sua alimentação e saúde, o que se torna impossível quando se tem muitos filhos. Em resumo, o filho passa a ser o grande investimento familiar, e por esta razão se torna alvo de pesada carga de responsabilidades, o que acaba tornando a infância uma fase angustiada e, consequentemente, medicamentalizada (FOUCAULT, 2008a, p. 335-6).

No que se refere ao aspecto político, o neoliberalismo trata de propor novas questões ao liberalismo de Adam Smith (século XVIII), que se definia pela demarcação de um espaço livre para que o mercado pudesse se desenvolver obedecendo a mecanismos naturais e 
espontâneos, capazes de estabelecer um padrão de verdade que possibilitava discernir sobre as práticas governamentais que são corretas ou incorretas. Isto porque, para o neoliberalismo, a grade econômica torna possível testar a ação governamental e verificar sua validade, permitindo "objetar à atividade do poder público seus abusos, seus excessos, suas inutilidades, seus gastos pletóricos.” (FOUCAULT, 2008a, p. 338)

Nesta perspectiva, o que se vê é uma crítica política permanente da ação política e da ação governamental; isto é, toda a ação do poder público passa a ser filtrada em termos de jogo de oferta e procura; em termos de eficácia, do custo que implica pela intervenção do poder público no mercado. Deste modo, a governamentalidade passa a ser alvo de uma cínica crítica mercantil, não mais exclusivamente política ou jurídica, e diante dela se rearranja, aperfeiçoa-se e mantém o desenvolvimento do neoliberalismo (FOUCAULT, 2008a, p. 338).

Portanto, seguindo-se esta linha, pode-se concluir que, enquanto no liberalismo clássico era essencial que o governo respeitasse a forma do mercado, no conhecido estilo deixar fazer, no neoliberalismo não se deixa o governo fazer, em nome de uma lei de mercado que permite aferir e avaliar cada uma de suas ações. Em termos foucaultianos, funda-se uma espécie de tribunal econômico permanente para julgar o governo. ${ }^{5}$

Além disso, é preciso compreender que se o liberalismo estabelecia espaços de liberdade, no sentido negativo de ausência de intervenção estatal nas relações, o neoliberalismo produz liberdades, que sequer eram imaginadas. Porém, ao produzir liberdades, também destrói liberdades; noutras palavras, controla permanentemente as liberdades, estabelecendo um número limitado de possibilidades para gozá-la, proporcionando a estranha sensação de que em tempo algum se foi tão livre e, ao mesmo tempo, de que toda esta liberdade se encontra tão condicionada, tão normalizada (FOUCAULT, 2008a, p. 86).

No que se refere à criminalidade e ao funcionamento da justiça penal, esta análise de comportamentos não econômicos, mediada pela grade da linguagem econômica, bem como a crítica e avaliação da ação governamental em termos de mercado, são responsáveis por uma superação da solução utilitarista-legalista apresentada pelos reformadores ${ }^{6}$ do século XVIII pela intervenção no mercado do crime.

Os reformadores, em sua crítica ao sistema penal a partir de uma lógica e uma racionalidade econômicas, teciam considerações sobre o custo da delinquência, da prática

\footnotetext{
5 "Enquanto o século XIX havia procurado estabelecer, em face e contra a exorbitância da ação governamental, uma espécie de jurisdição administrativa que permitisse aferir a ação do poder público em termos de direito, temos aqui uma espécie de tribunal econômico que pretende aferir a ação do governo em termos estritamente de economia e mercado." (FOUCAULT, 2008a, p. 339)

${ }^{6}$ Cf. BECCARIA, 2005 e BENTHAM, 2000.
} 
judiciária tal como funcionava, com a ineficácia do sistema punitivo de suplícios e banimentos, com intuito de projetar um sistema penal que tivesse o menor custo possível. Neste sentido, entenderam que a lei seria a resposta para os problemas apontados - seria a solução mais econômica para punir devida e eficazmente. Assim, o crime passou a ser definido como uma infração à lei, e as penas passaram a ser todas definidas em lei, de acordo com a gravidade do crime - aos tribunais só restaria aplicar a pena, prevista em lei de acordo com a gravidade do crime materializado e provado. Tratava-se de uma mecânica simplificada, óbvia, menos onerosa e mais eficiente em eliminar condutas nocivas da sociedade (FOUCAULT, 2008a, p. 341).

Nas palavras de Michel Foucault,

A lei, o mecanismo da lei foi adotado no poder penal, creio eu, no fim do século XVIII, como princípio da economia, no sentido ao mesmo tempo lato e preciso da palavra "economia". O homo penalis, o homem que é penalizável, o homem que se expõe à lei e pode ser punido pela lei, esse homo penalis é, no sentido estrito, um homo oeconomicus. E é a lei que permite, precisamente, articular o problema da penalidade com o problema da economia. (FOUCAULT, 2008a, p. 341)

Porém, é preciso atentar para o paradoxo que esta nova economia do crime estabeleceu, pois, se por um lado a lei sancionou exclusivamente atos, não se pode deslembrar que a existência da lei penal se justificava no propósito de punir, corrigir os indivíduos e dar exemplo a possíveis infratores. Aliás, é nesta contradição que se esboça a tendência interna ao sistema penal, que de maneira evidente se aproxima paulatinamente de uma modulação cada vez mais individualizante de aplicação da lei e, consequentemente, passa a problematizar psicológica, sociológica e antropologicamente aquele a quem se aplica a lei (FOUCAULT, 2008a, p. 341).

Portanto, no século XIX, o homo penalis se desdobra no homo criminalis, e a preconizada mecânica econômica da lei é substituída por uma inflação de conhecimentos, uma "inflação de discursos, uma multiplicação de instâncias, das instituições, dos elementos de decisão, e toda a parasitagem da sentença em nome da lei por medidas individualizantes em termo de norma." (FOUCAULT, 2008a, p. 342) Trata-se da estruturação da chamada escola etiológica de direito penal, que ganha em Cesare Lombroso (2013) seu expoente mais caricato.

Ressalte-se que essas mudanças ocorridas durante os séculos XVIII e XIX no sistema penal denotam que a sua organização a partir de uma racionalidade econômica leva inevitavelmente à concretização de um direito penal do autor e não do fato, como se pretendia. Isso faz com que o sistema penal se direcione à punição dos inimigos da sociedade, 
daqueles indivíduos considerados perigosos e, consequentemente, indesejáveis num certo contexto social (ZAFFARONI, 2007, p. 11).

Os neoliberais buscam superar o paradoxo criado por este projeto em que a utilidade toma forma jurídica e o direito se constrói a partir do cálculo de utilidade, retomam os problemas relativos ao homo oeconomicus para problematizar o crime exclusivamente no âmbito econômico, tal como faz Gary Becker (1968), enunciando que o crime é toda a ação que faz o indivíduo correr o risco de ser condenado a uma pena, ou mais acertadamente, crime é toda a ação que pode ser economicamente útil ou não ao indivíduo, considerado o risco de ser condenado a uma pena, bem como aquilo que será governamentalizado pelo Estado, no mesmo cálculo de utilidade econômica.

Portanto, pode-se concluir que na análise dos neoliberais não há mais uma preocupação artificial com os atos criminosos e sua correção, mas com o indivíduo que busca lucrar com o crime e corre o risco de ser condenado, com o custo de sua condenação, com o risco de perda econômica que pode ser infligida por um sistema penal. Neste contexto, o Estado se preocupa com a forma de reação a esta oferta do crime, com os instrumentos para intervir no mercado do crime, com quantos delitos devem ser permitidos, com quantos delinquentes devem ser punidos, quais ações oferecem perigo ao seu desenvolvimento econômico (FOUCAULT, 2008a, p. 350 et seq.).

Enfim, para que possa ser bem sucedido nesta reação à oferta de crime, o Estado deve estabelecer o máximo controle da população, e a prática dos biopoderes é essencial para que possa cumprir tal intento. Note-se que esse controle pode ser verificado numa série de procedimentos de cadastramento estabelecidos pelo aparato estatal, tal como já foi mencionado. Contudo, sem dúvida alguma, na esfera do sistema penal, os mecanismos que evidentemente se prestam à expansão de tal controle são os substitutivos penais e as medidas cautelares, recentemente ampliadas no Brasil, na medida em que mantêm os alvos do sistema penal cadastrados, observados, vigiados, examinados.

\section{A BANALIZAÇÃO DA CUSTÓDIA CAUTELAR NO BRASIL E A APROVAÇÃO APRESSADA DA LEI 12403/2011}

As medidas cautelares buscam garantir o regular desenvolvimento do processo penal e, por conseguinte, a eficaz atuação do poder de punir. 
Dessa forma, vislumbra-se que a tutela cautelar penal é instrumental ao processo de conhecimento ou de execução penal, de modo que existe tão somente para alcançar as finalidades acima apontadas.

Na visão de Piero Calamandrei (2005, p. 45), se todas as medidas jurisdicionais se constituem num instrumento do direito material, que somente possui atuação por meio delas (princípio da indefectibilidade da jurisdição), nas providências cautelares se encontra uma instrumentalidade qualificada; ou seja, uma instrumentalidade elevada ao quadrado, pois se constituem como um meio predisposto para o melhor exercício da providência definitiva: as providências cautelares são, portanto, em relação à finalidade última da função jurisdicional, instrumento do instrumento.

A aplicação de uma medida cautelar pessoal, na esteira do que assenta Aury Lopes Jr. (2011), exige o preenchimento dos requisitos do fumus commissi delicti e periculum libertatis. Em outras palavras, para a decretação da medida cautelar pessoal exige-se, respectivamente, a demonstração, a partir de dados concretos, de que se está diante da prática de um injusto penal, em tese cometido pelo investigado/acusado, e de que a liberdade deste coloca em risco o normal desenvolvimento do processo criminal e/ou a eventual aplicação da lei penal.

Tal exigência, por elementar, decorre do princípio da presunção de inocência (BRASIL, 1988, artigo $5^{\circ}$, inciso LV), o qual se constitui num cânone processual penal que opera em dois sentidos: a) em primeiro lugar, não permite que o acusado seja submetido a penas antecipadas ou medidas análogas; b) em segundo lugar, projeta sobre a acusação o ônus de provar os fatos penalmente qualificados e, em caso de dúvida, serve de fundamento à absolvição do acusado (CORDERO, 2000, p. 398).

A consequência da adoção do princípio da presunção de inocência impõe, portanto, que ninguém poderá sofrer antecipadamente os efeitos de uma eventual condenação, e as prisões provisórias só têm sentido enquanto cumprirem a função cautelar em relação ao processo penal de conhecimento, garantindo a eficácia da prestação jurisdicional, se presentes os seus requisitos e fundamentos.

Por este motivo, a prisão cautelar deverá ser medida excepcional a ser decretada quando demonstrada concretamente sua necessidade para assegurar o regular desenvolvimento do processo ou a futura aplicação da lei penal. 
Apesar disso, verifica-se o estarrecedor número de presos provisórios no país. Em 2010 havia em torno de 209.000 e atualmente há $232.738^{7}$, o que aponta para a banalização da custódia cautelar, normalmente fundamentada na periculosidade do agente, na repercussão social do fato ou, paradoxalmente, na inaceitável desculpa da necessidade de se garantir a segurança do acusado contra reações enfurecidas da população, comovida ante as circunstâncias do acontecimento penalmente relevante. ${ }^{8}$

Esse número assustador de presos provisórios, somado às escancaradas deficiências do sistema carcerário do país, resultou na apressada aprovação da Lei 12403/11 (BRASIL, 2011), que por sua vez estabeleceu uma série de medidas cautelares pessoais diversas da prisão.

Passados mais de três anos da sua vigência, resta saber quais foram as suas consequências práticas. É esse um dos temas caros ao presente estudo, porquanto, ao que indicam os dados abaixo explorados, as constatações foucaultianas de sociedade de controle e neoliberal parecem perfeitamente se encaixar à realidade brasileira, que faz morrer os perigosos ao seu desenvolvimento, isolando-os nos cárceres desumanos mesmo antes da própria condenação, ou que estabelece uma vigilância permanente, por meio das novas medidas cautelares alternativas.

\section{A EXPANSÃo do CONTROLE PENAL ESTABELECIDA PELO NOVO REGIME DAS MEDIDAS CAUTELARES PROCESSUAIS PENAIS}

Na última década, o Código de Processo Penal brasileiro - CPP (BRASIL, 1941) sofreu quatro reformas pontuais. Em 2008, pelas Leis n ${ }^{\text {os }} 11689,11690$ e 11719 (BRASIL, 2008a, b e c), que alteraram mais de 100 artigos e modificaram direta ou indiretamente todos os ritos procedimentais previstos naquela legislação, e, em 2011, pela Lei n ${ }^{\circ} 12403$ (BRASIL, 2011), que alterou substancialmente o título IX do Código, denominando-o de "da prisão, das medidas cautelares e da liberdade provisória”.

Como aponta o professor Aury Lopes Jr. (2011, p. 1-4), a despeito de terem pontos positivos, essas reformas pontuais inviabilizaram a aprovação de um novo Código de Processo Penal capaz de romper de uma vez por todas com a matriz autoritária, sob a qual fora elaborado o CPP de 1941, em plena ditadura getulista.

\footnotetext{
7 Dados de junho de 2014, pelo Conselho Nacional de Justiça. Disponível em: $<$ http://www.cnj.jus.br/images/imprensa/pessoas_presas_no_brasil_final.pdf>. Acesso em: 29 ago. 2014.

${ }^{8}$ Sobre o tema, cf. LOPES JUNIOR, 2011, p. 81-9, e CÂAMARA, 2012, p. 130-5.
} 
A Lei $n^{\circ}$ 12403/11 (BRASIL, 2011), oriunda do Projeto de Lei 4208/2001 (BRASIL, 2001), que foi alterado significativamente no Congresso Nacional, trouxe transformações positivas para o campo das cautelares pessoais, quais sejam: (i) a adoção de um modelo polimorfo, que afastou o binário consistente na prisão cautelar/liberdade provisória, oferecendo ao juiz um rol de medidas alternativas à prisão preventiva ${ }^{9}$; (ii) a disposição do flagrante no seu devido lugar de prisão pré-cautelar ou subcautelar, preparatória da prisão preventiva, e (iii) o resgate da fiança, com a possibilidade de a própria autoridade policial arbitrá-la nos casos em que a pena máxima cominada ao delito não supere os quatro anos.

Diante dessa reforma e já transcorridos mais de três anos, cumpre indagar se essas inovações, mormente a inclusão das medidas cautelares alternativas à prisão, surtiram, na prática, o efeito descarcerizador tão propalado quando da sua entrada em vigor.

Ora, cotejando os dados do sistema carcerário disponibilizados pelo Sistema Integrado de Informações Penitenciárias (InfoPen) e pelo Conselho Nacional de Justiça (CNJ), parece que, uma vez mais, a tentativa legislativa de diminuição da população carcerária por meio de medidas alternativas, publicizada no discurso oficial e midiático, não resultou frutífera.

Aliás, analisando tais dados, é possível observar que o número da população carcerária, especialmente dos presos provisórios, continua crescendo numa escala impressionante. ${ }^{10}$

Dados de 12/2009:

\begin{tabular}{|l|l|l|l|}
\hline & População carcerária & Presos provisórios & Percentual \\
\hline Brasil & 473.626 & $\begin{array}{l}152.621+56.514= \\
\mathbf{2 0 9 . 1 3 5}\end{array}$ & $44,16 \%$ \\
\hline Paraná & 37.440 & $3.194+15.274=\mathbf{1 8 . 4 6 8}$ & $49,33 \%$ \\
\hline Santa Catarina & 13.340 & $\mathbf{3 . 8 4 2}$ & $28,80 \%$ \\
\hline
\end{tabular}

\footnotetext{
${ }^{9}$ A Lei $\mathrm{n}^{\mathrm{o}}$ 12403/11 estabeleceu as seguintes medidas cautelares diversas da prisão: comparecimento periódico em juízo, para informar e justificar atividades; proibição de acesso ou frequência a determinados lugares, para evitar novos crimes; proibição de manter contato com pessoa determinada, em razão de circunstâncias relativas ao fato imputado; proibição de ausentar-se da comarca do juízo processante, quando a permanência seja conveniente ou necessária para a investigação ou instrução; recolhimento domiciliar noturno e nos dias de folga, quando o acusado tem trabalho fixo; suspensão do exercício da função pública, para evitar novos crimes; suspensão de atividades econômicas ou financeiras, a fim de impedir reiterações criminosas; internação provisória do acusado ou indiciado semi-imputável ou inimputável, nas hipóteses de crimes praticados mediante violência ou grave ameaça e quando houver risco de reiteração; monitoração eletrônica; proibição de ausentar-se do país, acompanhada da entrega do passaporte, e fiança para assegurar o comparecimento aos atos do processo. (BRASIL, 2011)

${ }^{10}$ Dados disponíveis em: <http://portal.mj.gov.br/main.asp?View=\%7BD574E9CE-3C7D-437A-A5B622166AD2E896\%7D\&Team=\&params $=$ itemID=\%7B2627128E-D69E-45C6-8198-

CAE6815E88D0\%7D;\&UIPartUID=\%7B2868BA3C-1C72-4347-BE11-A26F70F4CB26\%7D >. Acesso em: 29 ago. 2014. No presente artigo, fez-se um recorte dos dados referentes ao âmbito nacional, ao Estado do Paraná e ao Estado de Santa Catarina.
} 
Dados de 12/2010:

\begin{tabular}{|l|l|l|l|}
\hline & População carcerária & Presos provisórios & Percentual \\
\hline Brasil & 496.251 & $\begin{array}{l}164.683+50.546= \\
\mathbf{2 1 5 . 2 2 9}\end{array}$ & $43,37 \%$ \\
\hline Paraná & 35.955 & $3.117+16.205=\mathbf{1 9 . 3 2 2}$ & $53,74 \%$ \\
\hline Santa Catarina & 14.541 & $\mathbf{3 . 9 0 8}$ & $26,88 \%$ \\
\hline
\end{tabular}

Dados de 12/2011:

\begin{tabular}{|l|l|l|l|}
\hline & População carcerária & Presos provisórios & Percentual \\
\hline Brasil & 514.582 & $\mathbf{2 1 7 . 1 4 6}$ & $42,20 \%$ \\
\hline Paraná & 33.586 & $\mathbf{1 5 . 3 0 3}$ & $45,56 \%$ \\
\hline Santa Catarina & 14.974 & $\mathbf{3 . 9 9 2}$ & $26,66 \%$ \\
\hline
\end{tabular}

Dados de 2012:

\begin{tabular}{|l|l|l|l|}
\hline & População carcerária & Presos provisórios & Percentual \\
\hline Brasil & 548.003 & $\mathbf{2 2 9 . 0 6 5}$ & $41,80 \%$ \\
\hline Paraná & 31.312 & $\mathbf{1 1 . 7 0 1}$ & $37,37 \%$ \\
\hline Santa Catarina & 16.623 & $\mathbf{4 . 7 9 6}$ & $28,85 \%$ \\
\hline
\end{tabular}

Dados de $2014^{11}$ :

\begin{tabular}{|l|l|l|l|}
\hline & População carcerária & Presos provisórios & Percentual \\
\hline Brasil & 567.655 & $\mathbf{2 3 2 . 7 3 8}$ & $41,00 \%$ \\
\hline Paraná & 32.438 & $\mathbf{1 2 . 0 0 2}$ & $37,00 \%$ \\
\hline Santa Catarina & 16.366 & $\mathbf{4 . 9 0 0}$ & $29,94 \%$ \\
\hline
\end{tabular}

Explorando as estatísticas do período (2011 até 2014), verifica-se que a população carcerária continua a crescer e que a custódia cautelar especificamente, a despeito do ingresso, no ordenamento jurídico, de medidas cautelares diversas da prisão (BRASIL, 1941, art. 319, com redação dada pela Lei $\left.n^{\circ} 12403 / 11\right)$, mantém sua curva ascendente.

De fato, segundo pesquisa empírica realizada no Rio de Janeiro, publicada em 2013 e denominada Usos e abusos da prisão provisória no Rio de Janeiro: avaliação do impacto da Lei $12.403 / 2011^{12}$, a prisão provisória é de longe a medida cautelar mais adotada, e prevalece mesmo após a entrada em vigor da Lei 12403.

No referido estudo, os pesquisadores apontam que $79 \%$ das 4859 decisões analisadas, relativas a flagrantes de todos os tipos de crimes no ano de 2011, resultaram em privação da liberdade dos acusados e que, portanto, somente em $21 \%$ dos casos foram decretadas outras medidas cautelares.

O estudo ainda indica que o impacto da nova lei recaiu sobre os delitos de menor gravidade (delitos de violação de direito autoral, falsificação de sinal alfandegário, furto, receptação e estelionato), para os quais, a rigor, sequer haveria possibilidade da aplicação da

\footnotetext{
${ }^{11}$ Dados de junho de 2014, do Conselho Nacional de Justiça. Disponível em: $<$ http://www.cnj.jus.br/images/imprensa/pessoas_presas_no_brasil_final.pdf>. Acesso em: 29 ago. 2014.

${ }^{12}$ LEMGRUBER et al., 2013.
} 
prisão provisória ou outra medida alternativa, caso fosse levado a sério o princípio da proporcionalidade que rege as cautelares no processo penal. ${ }^{13}$

Dito de outra forma, o cotejo dos dados do sistema carcerário brasileiro fornecidos pelo InfoPen e pelo CNJ, bem como a pesquisa empírica realizada no Rio de Janeiro, demonstram que as medidas cautelares diversas da prisão em nada contribuíram para a diminuição do número de presos provisórios; ao contrário, aumentaram o controle penal também para os crimes menos graves, com o amplo cadastramento e vigilância impostos pelas medidas diversas da prisão.

Ora, isso significa que se continua a fazer morrer no cárcere os indivíduos considerados perigosos para o desenvolvimento econômico da sociedade brasileira, e a manter sob vigilância aqueles que algum dia podem representar tal perigo, impedindo-os de frequentar determinados lugares, de desenvolver certas atividades e de circular livremente, por meio da entrega dos passaportes, da monitoração eletrônica etc.

Portanto, pode-se dizer que essa falaciosa tentativa de diminuir a expressiva população carcerária brasileira, por intermédio das medidas cautelares diversas (BRASIL, 1941, art. 319), em verdade cumpriu uma função cara à sociedade de controle e neoliberal; qual seja, expandir o controle social pelas mais variadas tecnologias.

Aliás, não é de hoje que se buscam, ao menos no discurso, medidas alternativas ao encarceramento em massa. Como explica Augusto Jobim Amaral,

$$
\begin{aligned}
& \text { desde as penas pecuniárias, passando pela suspensão condicional da pena, e } \\
& \text { chegando até o livramento condicional, sucessivos mecanismos foram aplicados na } \\
& \text { tentativa de evitar a prisionalização, fato marcante no movimento político criminal } \\
& \text { pelo mundo a partir principalmente da década de setenta (AMARAL, 2010, p. 82). }
\end{aligned}
$$

Todavia, de nada adiantaram os mais variados substitutivos penais concebidos ao longo dos anos no Brasil; ao revés, o que ocorreu foi uma expressiva ampliação do controle social pelo sistema penal estatal.

Neste sentido, a Lei 9099/95 (BRASIL, 1995), que instituiu o Juizado Especial Criminal no âmbito estadual, se apresenta como exemplo mais contundente da expansão da gerência social pelo poder punitivo estatal.

Editada para dar cumprimento ao comando constitucional previsto no artigo 98, inciso I, da Constituição da República de 1988 (BRASIL, 1988), o referido diploma legal foi

\footnotetext{
${ }^{13}$ Sobre o princípio da proporcionalidade, explica Badaró (2014, p. 718) que "O juiz deverá também considerar a probabilidade de que seja imposta uma pena privativa de liberdade a ser executada em regime prisional. Somente no caso em que se anteveja, com base nos elementos concretos existentes nos autos, que o acusado terá que se submeter a uma pena privativa de liberdade, a prisão cautelar será proporcional ao provimento definitivo que visa assegurar".
} 
enaltecido por juristas em virtude das medidas alternativas nele previstas (composição civil, transação penal, suspensão condicional do processo), as quais teoricamente teriam caráter despenalizador. Como ironicamente pontua Maria Lucia Karam (2004, p. 49), “os entusiastas da lei 9.099/95, que, sem enxergar a ampliação do poder do Estado de punir, facilitada por esses institutos materializadores da antecipação da reação punitiva, a saudavam como portadora de medidas despenalizadoras".

De fato, os dados estatísticos indicam uma linha crescente de submissão de pessoas ao controle estatal por medidas alternativas, sem que do outro lado houvesse qualquer diminuição da população carcerária.

É o que explica Augusto Jobim Amaral a partir da análise dos dados fornecidos pelo Departamento Penitenciário Nacional - Depen:

\begin{abstract}
Se, em 95, primeiro ano de vigência dos juizados especiais criminais, já houve (além dos 1.692 cumprimentos de penas alternativas - penas restritivas de direito) o registro de 78.672 casos de medidas alternativas (composição civil, transação penal ou suspensão condicional do processo), os dados de 2002 - após um curto período de implementação da Lei 9.714/98, bem como passada a definição pela 10.259/01 já demonstravam um substancial aumento: 21.560 cumprimentos de penas alternativas somados aos 80.843 casos de execução de medidas alternativas. (...) Em 2009, os índices já apontavam para 126.273 o número de cumpridores de penas alternativas, chegando-se num total de 671.078 indivíduos sob a tutela do controle penal descarcerizado. - Nem por isso os níveis de encarceramento diminuíram -. A evolução da relação comparativa entre prisões e penas/medidas alternativas continua gritantemente crescente. Não é demais reafirmar que, já em 2009, chegávamos (somados aos dados da época de presos na casa de 473.626) à amplitude da teia penal no Brasil da ordem de 1.144.704 pessoas envolvidas (AMARAL, 2010, p. 82$3)$.
\end{abstract}

Conforme Salo de Carvalho (2014, p. 160), “inegavelmente, a evolução do controle punitivo formal não carcerário, instrumentalizado pelos substitutivos penais, é expressiva nas duas últimas décadas".

Para a criminologia crítica, "os substitutivos penais atuam como mecanismos de relegitimação do cárcere, reduzindo a potência do discurso anticarcerário em nome de alternativas politicamente viáveis" (CARVALHO, 2014, p. 160-1).

Note-se que tanto as medidas cautelares alternativas diversas da prisão quanto os substitutivos penais exigem, para sua concretização, o cadastramento minucioso dos seus beneficiários, uma verificação constante das atividades por eles desenvolvidas e uma vigilância ininterrupta, aumentando o controle penal e fortalecendo a biopolítica neoliberal. 


\section{CONCLUSÃO}

Como se viu, o propósito oficial das inovações determinadas pela Lei $\mathrm{n}^{\mathrm{o}}$ 12403/11 era tornar a prisão uma medida excepcional, para assegurar o desenvolvimento do processo e garantir, ao seu final, a eventual aplicação de uma pena, uma vez que a situação de superlotação dos cárceres brasileiros alcançou níveis inaceitáveis de violação dos direitos humanos.

Há muito tempo os criminólogos, juristas e jornalistas têm criticado o tratamento desumano dado aos presos no Brasil e reivindicado a modificação física das condições dos estabelecimentos prisionais, bem como a alteração legislativa para relegar à prisão apenas os condenados por crimes de evidente gravidade.

Então, quando aprovado o novo regime das cautelares penais, festejaram e imaginaram que uma grande revolução iria acontecer nos cárceres brasileiros, com a liberação daqueles presos provisórios que poderiam ver-se processar sob a vigência de uma cautelar diversa da prisão.

Entretanto, tais expectativas foram frustradas, na medida em que o número de prisões processuais não diminuiu e muitos indiciados e processados foram submetidos ao controle das medidas alternativas.

Neste sentido, percebe-se que a situação dos cárceres brasileiros não sofreu qualquer alteração e que as novas medidas cautelares estão justamente no caminho oposto, pois reforçaram sua precariedade, tornando-os ainda mais eficazes na tarefa de fazer morrer os indivíduos considerados perigosos, além de, simultaneamente, estabelecerem um controle ininterrupto sobre aqueles que representam um possível perigo.

Enfim, o neoliberalismo recebeu as críticas e rearranjou o seu aparato de aniquilamento daqueles vistos como inferiores pela sociedade brasileira contemporânea, tal como no Holocausto. Além disso, com a nova legislação das cautelares produziu liberdades, permitindo que muitos fossem investigados e processados sem a necessidade de se submeterem ao cárcere. Contudo, tais liberdades nunca foram tão condicionadas, tão vigiadas, como é próprio da sociedade de controle.

\section{REFERÊNCIAS}

AMARAL, Augusto Jobim do. Entre serpentes e toupeiras: a cultura do controle na contemporaneidade (ou sobre o caso do monitoramento eletrônico de presos no Brasil). Sistema Penal \& Violência - revista do Programa de Pós-Graduação em Ciências Criminais da PUCRS. Porto Alegre, vol. 2, n. 2, p. 75-89, julho/dezembro 2010. 
BADARÓ, Gustavo Henrique Righi Ivany. Processo Penal. 2 ed. Rio de Janeiro: Elsevier, 2014.

BAUMAN, Zygmunt. Comunidade: a busca de segurança no mundo atual. Tradução Plínio Dentzien. Rio de Janeiro: Zahar, 2003.

BECCARIA, Cesare. Dos delitos e das penas. Tradução Alexis Augusto Couto de Brito. São Paulo: QuartierLatin, 2005.

BECK, Ulrich. Sociedade de risco: rumo a uma outra modernidade. Tradução Sebastião Nascimento. São Paulo: Ed. 34, 2010.

BECKER, Gary. Crime and Punishment: An Economic Approach. The Journal of Political Economy, 1968, p. 169-207.

BENTHAM, Jeremy. $O$ panóptico. Tradução Tomaz Tadeu da Silva. Belo Horizonte: Autêntica, 2000.

BRASIL. Conselho Nacional de Justiça. Novo diagnóstico de pessoas presas no Brasil. Brasília/DF, junho de 2014.2 Disponível em: $<$ http://www.cnj.jus.br/images/imprensa/pessoas_presas_no_brasil_final.pdf $>$. Acesso em: 29 ago. 2014.

. Constituição da República Federativa do Brasil de 1988. Diário Oficial da União, Brasília, DF, 05 out. 1988.1 Disponível $<$ http://www.planalto.gov.br/ccivil_03/constituicao/Constituicao.htm>. Acesso em: 29 ago. 2014.

Decreto-Lei N $\mathrm{N}^{\mathrm{3}}$ 3.689, de 3 de outubro de 1941. Código de Processo Penal. Diário Oficial da União, Rio de Janeiro, DF, 13 out. 1941, retificado em 24 out. 1941. Disponível em: <http://www.planalto.gov.br/ccivil_03/decreto-lei/del3689.htm>. Acesso em: 29 ago. 2014.

Lei 11.689, de 9 de junho de 2008. Altera dispositivos do Decreto-Lei no 3.689, de 3 de outubro de 1941 - Código de Processo Penal, relativos ao Tribunal do Júri, e dá outras providências. Diário Oficial da União, Brasília, DF, 10 jun. 2008a. Disponível em: $<$ http://www.planalto.gov.br/ccivil_03/_Ato2007-2010/2008/Lei/111689.htm>. Acesso em: 29 ago. 2014.

Lei 11.690, de 9 de junho de 2008. Altera dispositivos do Decreto-Lei no 3.689, de 3 de outubro de 1941 - Código de Processo Penal, relativos à prova, e dá outras providências. Diário Oficial da União, Brasília, DF, 10 jun. 2008b. Disponível em: $<$ http://www.planalto.gov.br/ccivil_03/_ato2007-2010/2008/lei/111690.htm>. Acesso em: 29 ago. 2014.

Lei 11.719, de 20 de junho de 2008. Altera dispositivos do Decreto-Lei no 3.689, de 3 de outubro de 1941 - Código de Processo Penal, relativos à suspensão do processo, emendatio libelli, mutatio libelli e aos procedimentos. Diário Oficial da União, Brasília, DF, 23 jun. 2008c. Disponível em: <http://www.planalto.gov.br/ccivil_03/_Ato20072010/2008/Lei/L11719.htm>. Acesso em: 29 ago. 2014. 
. Lei 12.403, de 4 de maio de 2011. Altera dispositivos do Decreto-Lei no 3.689, de 3 de outubro de 1941 - Código de Processo Penal, relativos à prisão processual, fiança, liberdade provisória, demais medidas cautelares, e dá outras providências. Diário Oficial da União, Brasília, DF, 5 maio 2011. Disponível em: $<$ http://www.planalto.gov.br/ccivil_03/_ato2011-2014/2011/lei/112403.htm>. Acesso em: 29 ago. 2014.

Lei 9.099, de 26 de setembro de 1995. Dispõe sobre os Juizados Especiais Cíveis e Criminais e dá outras providências. Diário Oficial da União, Brasília, DF, 27 set. 1995. Disponível em: < http://www.planalto.gov.br/ccivil_03/leis/19099.htm>. Acesso em: 29 ago. 2014.

Ministério da Justiça. Execução penal - Sistema prisional. Brasília/DF, 2012. Disponível em: <http://portal.mj.gov.br/main.asp?View=\%7BD574E9CE-3C7D-437A-A5B622166AD2E896\%7D\&Team $=\&$ params $=$ itemID=\%7B2627128E-D69E-45C6-8198CAE6815E88D0\%7D;\&UIPartUID=\%7B2868BA3C-1C72-4347-BE11A26F70F4CB26\%7D>. Acesso em: 29 ago. 2014.

. Projeto de Lei 4.208, de 12 de março de 2001. Altera dispositivos do Decreto-Lei ${ }^{\circ}$ 3.689, de 3 de outubro de 1941 - Código de Processo Penal, relativos à prisão, medidas cautelares e liberdade, e dá outras providências. Diário da Câmara dos Deputados, Brasília, DF, 30 mar. 2001. Disponível em: $<$ http://www.camara.gov.br/proposicoesWeb/prop_mostrarintegra;jsessionid=9E2C247FC57 B221309DFE110395D40CD.proposicoesWeb2?codteor $=401942 \&$ filename $=P L+4208 / 2001>$. Acesso em: 29 ago. 2014.

CALAMANDREI, Piero. Introducción al Estudio Sistemático de las Providencias Cautelares. Lima: ARA Editores, 2005.

CARVALHO, Salo. Substitutivos penais na era do grande encarceramento. Disponível em: $<$ https://www.academia.edu/2758949/Substitutivos_Penais_na_Era_do_Grande_Encarcerame ntoacademia.edu>. Acesso em: 29 ago. 2014.

CASTELLS, Manuel. Sociedade em rede. Tradução Roneide Venancio Majer. 8 ed. São Paulo: Paz e Terra, 2005.

CORDERO, Franco. Procedimiento Penal. 2 vols. Tradução Jorge Guerrero. Bogotá: Temis, 2000 .

DELEUZE, Gilles. Conversações. Rio de Janeiro: Ed. 34, 1996.

DUARTE, André. Foucault e as novas figuras da biopolítica: o fascismo contemporâneo. Para uma vida não fascista. Org. Margareth Rago e Alfredo Veiga-Neto. Belo Horizonte: Autêntica, 2009.

EWALD, François. Foucault: A norma e o direito. Tradução António Fernando Cascais. Lisboa: Veja, 1993.

FONSECA, Marcio Alves da. Michel Foucault e o direito. São Paulo: Max Limonad, 2002. 
FOUCAULT, Michel. A governamentalidade. Microfísica do poder. Tradução e Org. Roberto Machado. 13. ed. Rio de Janeiro: Graal, 1999.

- Aula de 14 de fevereiro de 1979. O nascimento da biopolítica (Curso dado no Collège de France em 1978-9). Tradução Eduardo Brandão. São Paulo: Martins Fontes, 2008a, p. 179-219.

. Aula de 17 de março de 1976. Em defesa da sociedade. Tradução Maria Ermantina Galvão. São Paulo: Martins Fontes, 1999, p. 285-315.

. Aula de 21 de janeiro de 1976. Em defesa da sociedade. Tradução Maria Ermantina Galvão. São Paulo: Martins Fontes, 1999, p. 49-73.

Aula de 21 de março de 1979. O nascimento da biopolítica (Curso dado no Collège de France em 1978-9). Trad. Eduardo Brandão. São Paulo: Martins Fontes, 2008a, p. 329363.

. Aula de 24 de janeiro de 1979. O nascimento da biopolítica (Curso dado no Collège de France em 1978-9). Tradução Eduardo Brandão. São Paulo: Martins Fontes, 2008a, p. 71 101.

. A verdade e as formas jurídicas. Tradução Roberto Cabral de Melo Machado e Eduardo Jardim Moraes. Rio de Janeiro: Nau, 1996.

. La 'gouvernementalité'. Dits et Écrits. Org. Daniel Defert et François Ewald. Paris: Gallimard, 1994a, v. III.

Segurança, território e população (Curso dado no Collège de France em 1977-8). Traduçaõ Eduardo Brandão. São Paulo: Martins Fontes, 2008 b.

. Vigiar e punir: a história da violência nas prisões. Tradução Raquel Ramalhete. 11. ed. Petrópolis: Vozes, $1994 b$.

; FARGE, Arlette. Les désordres de famille. Paris: Gallimard, 1982.

KARAM, Maria Lucia. Juizados Especiais Criminais: a concretização antecipada do poder de punir. São Paulo: Revista dos Tribunais, 2004.

LEMGRUBER, Julita; FERNANDES, Márcia; CANO, Ignacio; MUSEMECI, Leonarda. Uso e abusos da prisão provisória no Rio de Janeiro: avaliação do impacto da lei 12.403/2011. Disponível em: $<$ http://www.gecap.direitorp.usp.br/files/Usos_e_abusos_da_priso_provisria_no_Rio_de_Jane iro_Avaliao_do_impacto_da_Lei_12_4032011.pdf $>$. Rio de Janeiro, novembro de 2013. Acesso em: 29 ago. 2014.

LIPOVETSKY, Gilles; CHARLES, Sébastien. Os tempos hipermodernos. São Paulo: Barcarolla, 2004.

LOMBROSO, Cesare. O Homem delinquente. Tradução Sebastião José Roque. São Paulo: Ícone, 2013. 
LOPES JUNIOR, Aury. O novo regime jurídico da prisão processual, liberdade provisória e medidas cautelares diversas. Rio de Janeiro: Lumen Juris, 2011.

MUCHAIL, Salma Tannus. O lugar das instituição na sociedade disciplinar. Recordar Foucault. Org. Renato Ribeiro. São Paulo: Brasiliense, 1986.

ORDOVÁS, María José González. Politicas y estrategias urbanas: la distribuición del espacio privado y público en la ciudad. Madrid: Fundamentos, 2000.

SOUZA, Jessé. A ralé brasileira: quem é e como vive. Belo Horizonte: Editora UFMG, 2011.

ZAFFARONI, E. Raúl. O inimigo no direito penal. Tradução Sérgio Lamarão. 2. ed. Rio de Janeiro: Revan, 2007.

\title{
THE EXPANSION OF CONTROL THROUGH THE ALTERNATIVE PRECAUTIONARY PERSONAL MEASURES
}

\begin{abstract}
This article aims to analyze how the personal precautionary measures, alternative to imprisonment under Law $\mathrm{n}^{0} 12.403 / 11$, were responsible for the expansion of social control exercised by the criminal justice system in Brazil. From reading the works of Michel Foucault, this expansion of punitive control is assigned to the contemporary experience of control society in Western countries, which ensures its maintenance with the establishment of a biopolitics and the neoliberalism. This denotes how the new precautionary measures match with this new social order, which establishes a permanent surveillance over individuals.
\end{abstract}

KEYWORDS: Alternative personal precautionary measures. Biopolitics. Control Society. Neoliberalism. 